\title{
Article \\ Reduction of Conduction Velocity in Patients with Atrial Fibrillation
}

\author{
Annejet Heida ${ }^{1}$, Mathijs S. van Schie ${ }^{1}$, Willemijn F. B. van der Does ${ }^{1}$, Yannick J. H. J. Taverne ${ }^{2}$, \\ Ad J. J. C. Bogers ${ }^{2}$ and Natasja M. S. de Groot ${ }^{1, *(D)}$ \\ 1 Erasmus Medical Center, Department of Cardiology, 3015 GD Rotterdam, The Netherlands; \\ a.heida@erasmusmc.nl (A.H.); m.vanschie@erasmusmc.nl (M.S.v.S.); \\ w.vanderdoes@erasmusmc.nl (W.F.B.v.d.D.) \\ 2 Erasmus Medical Center, Department of Cardiothoracic Surgery, 3015 GD Rotterdam, The Netherlands; \\ y.j.h.j.taverne@erasmusmc.nl (Y.J.H.J.T.); a.j.j.c.bogers@erasmusmc.nl (A.J.J.C.B.) \\ * Correspondence: n.m.s.degroot@erasmusmc.nl; Tel.: +31-10-7035018; Fax: +31-10-7035258
}

check for updates

Citation: Heida, A.; van Schie, M.S.; van der Does, W.F.B.; Taverne, Y.J.H.J.; Bogers, A.J.J.C.; de Groot, N.M.S. Reduction of Conduction Velocity in Patients with Atrial Fibrillation. J. Clin. Med. 2021, 10, 2614. https:// doi.org/10.3390/jcm10122614

Academic Editor: Patrizio Mazzone

Received: 13 May 2021

Accepted: 9 June 2021

Published: 14 June 2021

Publisher's Note: MDPI stays neutral with regard to jurisdictional claims in published maps and institutional affiliations.

Copyright: (c) 2021 by the authors. Licensee MDPI, Basel, Switzerland. This article is an open access article distributed under the terms and conditions of the Creative Commons Attribution (CC BY) license (https:// creativecommons.org/licenses/by/ $4.0 /)$.

\begin{abstract}
It is unknown to what extent atrial fibrillation (AF) episodes affect intra-atrial conduction velocity $(\mathrm{CV})$ and whether regional differences in local $\mathrm{CV}$ heterogeneities exist during sinus rhythm. This case-control study aims to compare CV assessed throughout both atria between patients with and without AF. Patients $(n=34)$ underwent intra-operative epicardial mapping of the right atrium (RA), Bachmann's bundle (BB), left atrium (LA) and pulmonary vein area (PVA). CV vectors were constructed to calculate median CV in addition to total activation times (TAT) and unipolar voltages. Biatrial median CV did not differ between patients with and without AF $(90 \pm 8 \mathrm{~cm} / \mathrm{s}$ vs. $92 \pm 6 \mathrm{~cm} / \mathrm{s}$, $p=0.56)$; only BB showed a CV reduction in the AF group (79 $\pm 12 \mathrm{~cm} / \mathrm{s}$ vs. $88 \pm 11 \mathrm{~cm} / \mathrm{s}, p=0.02)$. In patients without $\mathrm{AF}$, there was no predilection site for the lowest $\mathrm{CV}\left(\mathrm{P}_{5}\right)(\mathrm{RA}: 12 \%$; $\mathrm{BB}$ : $29 \%$; LA: 29\%; PVA: 29\%). In patients with AF, lowest CV was most often measured at BB (53\%) and ranged between 15 to $22 \mathrm{~cm} / \mathrm{s}$ (median: $20 \mathrm{~cm} / \mathrm{s}$ ). Lowest CVs were also measured at the LA (18\%) and PVA (29\%), but not at the RA. AF was associated with a prolonged TAT $(p=0.03)$ and decreased voltages $\left(\mathrm{P}_{5}\right)$ at $\mathrm{BB}(p=0.02)$. BB was a predilection site for slowing of conduction in patients with AF. Prolonged TAT and decreased voltages were also found at this site. The next step will be to determine the relevance of a reduced $\mathrm{CV}$ at $\mathrm{BB}$ in relation to $\mathrm{AF}$ development and maintenance.
\end{abstract}

Keywords: atrial fibrillation; electrophysiology; atrial remodeling; conduction velocity

\section{Introduction}

Intra-atrial conduction velocity $(\mathrm{CV})$ is determined by ion channel properties, cellto-cell coupling, wavefront geometry and muscle thickness [1,2]. Areas of reduced CV are associated with initiation and perpetuation of atrial fibrillation (AF) [3]. In 12 patients with ischemic heart disease or Wolff-Parkinson-White syndrome who underwent cardiac surgery, the average CV measured during sinus rhythm (SR) at the right atrial free wall in an area of $3 \times 4 \mathrm{~cm}^{2}$ was $88 \mathrm{~cm} / \mathrm{s}$ [4]. A comparable average CV of $89 \pm 13 \mathrm{~cm} / \mathrm{s}$ was found at Bachmann's Bundle (BB) in 185 patients undergoing coronary artery bypass surgery [5].

There is only one report on comparison of CV during SR between patients with and without AF [6]. In this endocardial mapping study, paroxysmal AF was associated with a reduction of CV to $60 \pm 12 \mathrm{~cm} / \mathrm{s}$ at the right atrium (RA) and to $51 \pm 11 \mathrm{~cm} / \mathrm{s}$ at the left atrium (LA) compared to patients with atrioventricular nodal re-entrant tachycardia and WolffParkinson-White syndrome, respectively (RA: $83 \pm 13 \mathrm{~cm} / \mathrm{s}$ and LA: $70 \pm 10 \mathrm{~cm} / \mathrm{s}$ ) [6]. Additionally, the basal, septal and annular regions of the RA showed a reduction in CV in patients with paroxysmal AF (basal region: $54 \pm 19 \mathrm{~cm} / \mathrm{s}$ vs. $82 \pm 25 \mathrm{~cm} / \mathrm{s}$; septal region: $64 \pm 20 \mathrm{~cm} / \mathrm{s}$ vs. $93 \pm 32 \mathrm{~cm} / \mathrm{s}$; annular region: $60 \pm 12 \mathrm{~cm} / \mathrm{s}$ vs. $83 \pm 13 \mathrm{~cm} / \mathrm{s}$, all $p<0.05$ [6]. However, mapping was performed at only a limited number of sites at the RA 
and LA. Remarkably, the CV in this control group was much lower than CVs assessed in the studies described above.

To date, it is unknown to what extent $\mathrm{AF}$ episodes affect intra-atrial $\mathrm{CV}$ and whether there are regional differences in local $\mathrm{CV}$ during $\mathrm{SR}$ at the RA, BB and the LA including the pulmonary vein area (PVA). The aim of our case-control study is therefore to compare $\mathrm{CV}$ assessed at a high-resolution scale throughout both atria between patients with AF and without atrial tachyarrhythmias and to investigate which region is most affected by AF episodes.

\section{Materials and Methods}

\subsection{Study Population and Setting}

The study population consisted of participants undergoing elective open-heart surgery in the Erasmus Medical Center. Indications for elective cardiac surgery were either coronary artery disease, aortic valve- or mitral valve disease, or a combination of these. The case group consisted of patients with a history of documented AF. All SR recordings in this group were made after electrical cardioversion. The control group consisted of patients without atrial tachyarrhythmias. Participants were matched based on known confounders of intra-atrial conduction disorders, i.e., age [7], BMI [8] and left atrial enlargement [9]. Echocardiographic images were used to identify atrial dilatation. Participants were enrolled between March 2012 and April 2018. This study is approved by the institutional Medical Ethical Committee (resp. MEC 2010-054 [10] and MEC 2014-393 [11]). Written informed consent was obtained from all patients prior to the surgical procedure. The study complied with the Declaration of Helsinki. Clinical data were extracted from electronic patient files.

\subsection{Mapping Procedure}

As previously described, high-resolution epicardial mapping was performed during open heart surgery [12]. A bipolar pacemaker wire was temporarily attached to the right atrial free wall to function as a reference electrode. A steel wire was fixed in the thoracic subcutaneous tissue serving as an indifferent electrode. Epicardial mapping was performed using an unipolar 128- or a 192-electrode array (electrode diameter respectively 0.65 and $0.45 \mathrm{~mm}$, interelectrode distances of $2 \mathrm{~mm}$ ) and following a predefined scheme (Figure 1A), covering the epicardial surface of the RA (from the inferior caval vein up to the right atrial appendage, perpendicular to the caval veins), PVA (from the sinus transversus, alongside the borders of the pulmonary veins towards the atrioventricular groove), LA (from the lower border of the left pulmonary vein along the left atrioventricular groove towards the left atrial appendage) and BB (from the tip of left atrial appendage behind the aorta towards the superior cavo-atrial junction).

At each site, five seconds of SR mapping were recorded, including unipolar epicardial electrograms, a surface electrocardiogram, a bipolar reference electrogram and a calibration signal (amplitude: $2 \mathrm{mV}$, duration: $1000 \mathrm{~ms}$ ). Recordings were sampled with a rate of $1 \mathrm{kHz}$, amplified (gain: 1000), filtered (bandwidth: $0.5-400 \mathrm{~Hz}$ ), analogue-to-digital-converted (16-bits) and stored on a hard disk.

\subsection{Mapping Data Processing}

The steepest negative slopes of all atrial potentials were automatically annotated using custom-made mapping software when the amplitude exceeded twice the signal-to-noise ratio $[5,13]$. For each electrode, the local activation time was determined and color-coded activation maps were reconstructed as illustrated in Figure 1b. All annotations were visually verified. Premature extrasystolic and aberrant beats were excluded from analysis, along with mapping sites in which less than $50 \%$ was annotated. Areas of simultaneous activation were excluded from analysis in order to avoid inclusion of far field potentials. 

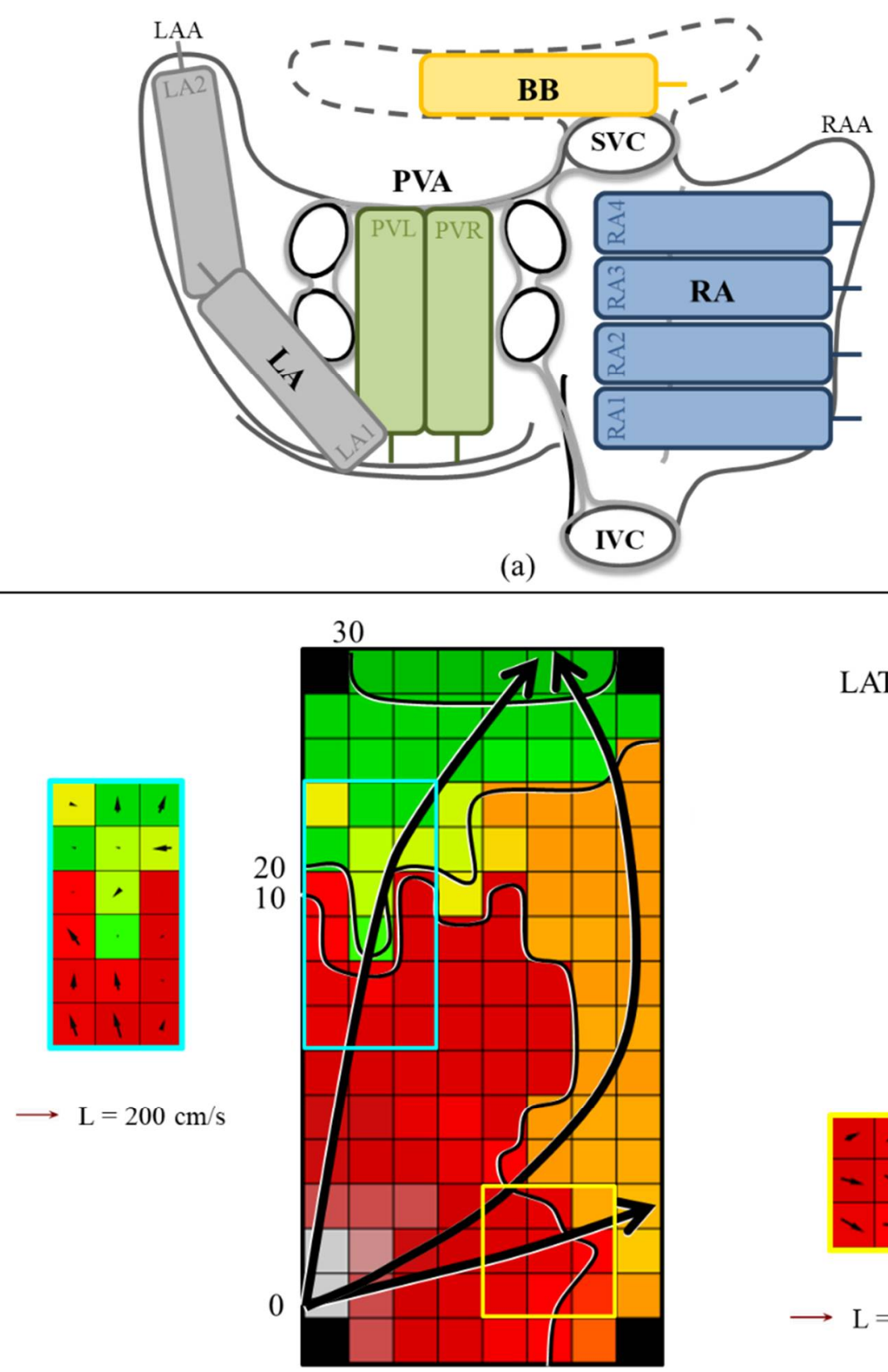

LAT (ms)

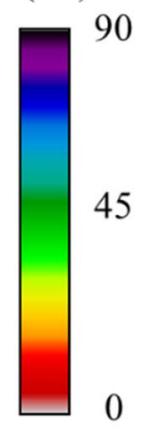

(b)

Figure 1. Method of epicardial mapping. (a) Mapping scheme on a schematic posterior view of the RA, BB, LA and PVA; (b) an example of a color-coded activation map with isochrones (black lines) drawn at $10 \mathrm{~ms}$. The black arrow indicates the main wave direction. Examples of the corresponding CV map using discrete velocity vectors are shown next to the activation map. CV vectors are depicted per electrode. $\mathrm{cm} / \mathrm{s}=$ centimeter $/$ second; $\mathrm{ms}=$ milliseconds; $\mathrm{BB}=\mathrm{Bachmann}$ 's Bundle; $\mathrm{CT}=$ conduction time; IVC = inferior vena cava; $\mathrm{L}=$ length; $\mathrm{LA}=$ left atrium; LAA = left atrial appendage; LAT = local activation time; $\mathrm{PVA}=$ pulmonary vein area; $\mathrm{PVL}=$ left pulmonary vein; $\mathrm{PVR}=$ right pulmonary vein; $\mathrm{RA}=$ right atrium; RAA = right atrial appendage; SVC = superior vena cava.

\subsection{Calculation of Local Conduction Velocities}

Local CV was computed as an average of velocity estimations between neighbouring electrodes (longitudinal, transversal and diagonal) using discrete velocity vectors as previously described by van Schie et al. [14]. Relative frequency distribution histograms of CVs were constructed to calculate median $C V$ and variance of $C V\left(\Delta P_{5}-P_{95}\right)$. For identification 
of areas of 'slow conduction', the 5th percentiles of the relative frequency distribution of CVs were determined. Additionally, the total activation times (TAT) of both atria and for each mapping site separately was determined by relating the first and last local activation time to the reference electrode. To compare voltage characteristics between patients with and without AF, we measured the peak-to-peak amplitude of the steepest deflection of each unipolar potential to construct relative frequency histograms. For determination of 'low voltage', we calculated the 5th percentile of the relative frequency distribution histograms of the voltages of all unipolar potentials.

\subsection{Statistical Analysis}

Statistical analysis was performed with SPSS version 25 (IBM Corporation, Armonk, NY, USA). All data were tested for normality using Shapiro-Wilk test. Continuous normally distributed data were expressed as mean \pm standard deviation and skewed data as median (interquartile range). To compare continuous parameters between the AF and no AF group, a paired samples t-test or Wilcoxon signed rank test was used. Categorical data is expressed as absolute numbers (percentages) and analyzed with (McNemar's symmetry) $\chi 2$ or McNemar's exact test, if applicable. A two-sided $p$-value of $<0.05$ was considered statistically significant.

\section{Results}

\subsection{Study Population}

As presented in Table 1, baseline characteristics between the AF group ( $n=17$, $73 \pm 7$ years; $11(64.7 \%)$ male) and no AF group ( $n=17,74 \pm 7$ years; 9 (52.9\%) male) did not differ (all $p \geq 0.05$ ). Participants in the AF group either had paroxysmal AF ( $n=6$, $27.3 \%)$, persistent $\mathrm{AF}(n=9,40.9 \%)$ or longstanding persistent $\mathrm{AF}(n=2,9.1 \%)$. Patients in the AF group had 1 month (0.5-4.0) AF before electrical cardioversion.

Table 1. Characteristics of Participants.

\begin{tabular}{|c|c|c|c|}
\hline & $\begin{array}{c}\text { AF Group } \\
(n=17)\end{array}$ & $\begin{array}{l}\text { No AF Group } \\
\quad(n=17)\end{array}$ & $p$ Value \\
\hline Age-Years (mean \pm SD) & $73 \pm 7$ & $74 \pm 7$ & 0.60 \\
\hline Male Sex- $n(\%)$ & $11(64.7)$ & $9(52.9)$ & 0.69 \\
\hline BMI-kg/m² (Median (IQR)) & $24.9(23.0-29.2)$ & $25.3(22.9-29.1)$ & 0.16 \\
\hline Underlying Heart Disease- $n(\%)$ & & & 1.00 \\
\hline IHD & $2(11.8)$ & $2(11.8)$ & \\
\hline (i)VHD & $15(88.2)$ & $15(88.2)$ & \\
\hline AVD & $2(11.8)$ & $3(17.6)$ & \\
\hline AVD and CAD & $2(11.8)$ & $2(11.8)$ & \\
\hline MVD & $9(52.9)$ & $7(41.2)$ & \\
\hline MVD and CAD & $2(11.8)$ & $3(17.6)$ & \\
\hline \multicolumn{4}{|l|}{ Echocardiography } \\
\hline LVF-n $(\%)$ & & & 1.00 \\
\hline Normal & $11(64.7)$ & $12(70.6)$ & \\
\hline Mild dysfunction & $3(17.6)$ & $2(11.8)$ & \\
\hline Moderate dysfunction & $3(17.6)$ & $3(17.6)$ & \\
\hline Severe dysfunction & $0(0.0)$ & $0(0.0)$ & \\
\hline Dilated LA >45 mm- $n(\%)$ & $11 / 13(84.6)$ & $9 / 15(60.0)$ & 0.41 \\
\hline \multicolumn{4}{|l|}{ Medication- $n(\%)$} \\
\hline Antiarrhythmic Drugs & & & 0.45 \\
\hline Class I & $0(0.0)$ & $0(0.0)$ & \\
\hline Class II & $11(64.7)$ & $7(41.2)$ & \\
\hline Class III & $4(23.5)$ & $0(0.0)$ & \\
\hline Class IV & $1(5.9)$ & $1(5.9)$ & \\
\hline Digoxin & $5(29.4)$ & $0(0.0)$ & 0.06 \\
\hline
\end{tabular}

$n=$ number; $\mathrm{SD}=$ standard deviation; $\mathrm{AF}=$ atrial fibrillation; $\mathrm{AVD}=$ aortic valve disease; $\mathrm{BMI}=$ Body Mass Index $\mathrm{CAD}=$ coronary artery disease; $\mathrm{IHD}=$ ischemic heart disease; $\mathrm{LA}=$ left atrium; $\mathrm{LVF}=$ left ventricular function; $\mathrm{MVD}=$ mitral valve disease; (i)VHD = (ischemic and) valvular heart disease. 


\subsection{Mapping Data Characteristics}

In total, 164,099 potentials (9192 (7421-11,250) potentials/patient) in the AF group and 150,015 potentials $(8533(7392-10,699)$ potentials/patient) in the no AF group were analyzed $(p=0.23)$. Due to simultaneous activation, $2.4 \%$ of the potentials in the AF group and $2.5 \%$ of the potentials in the no AF group were excluded from analysis. SR cycle length during epicardial mapping was $808 \pm 117 \mathrm{~ms}$ in the AF group and $881 \pm 213 \mathrm{~ms}$ in the no $\operatorname{AF}$ group $(p=0.17)$.

\subsection{Conduction Velocity Throughout Both Atria}

Figure 2A shows histograms of the relative frequency distribution of $\mathrm{CV}$ s throughout both atria for the AF group and no AF group separately. As can be seen, the CV histograms of both groups are comparable. Furthermore, Figure 2 demonstrates the median $\mathrm{CV}$ in the $\mathrm{AF}$ and no AF group for both atria (b) and for each location separately (c).
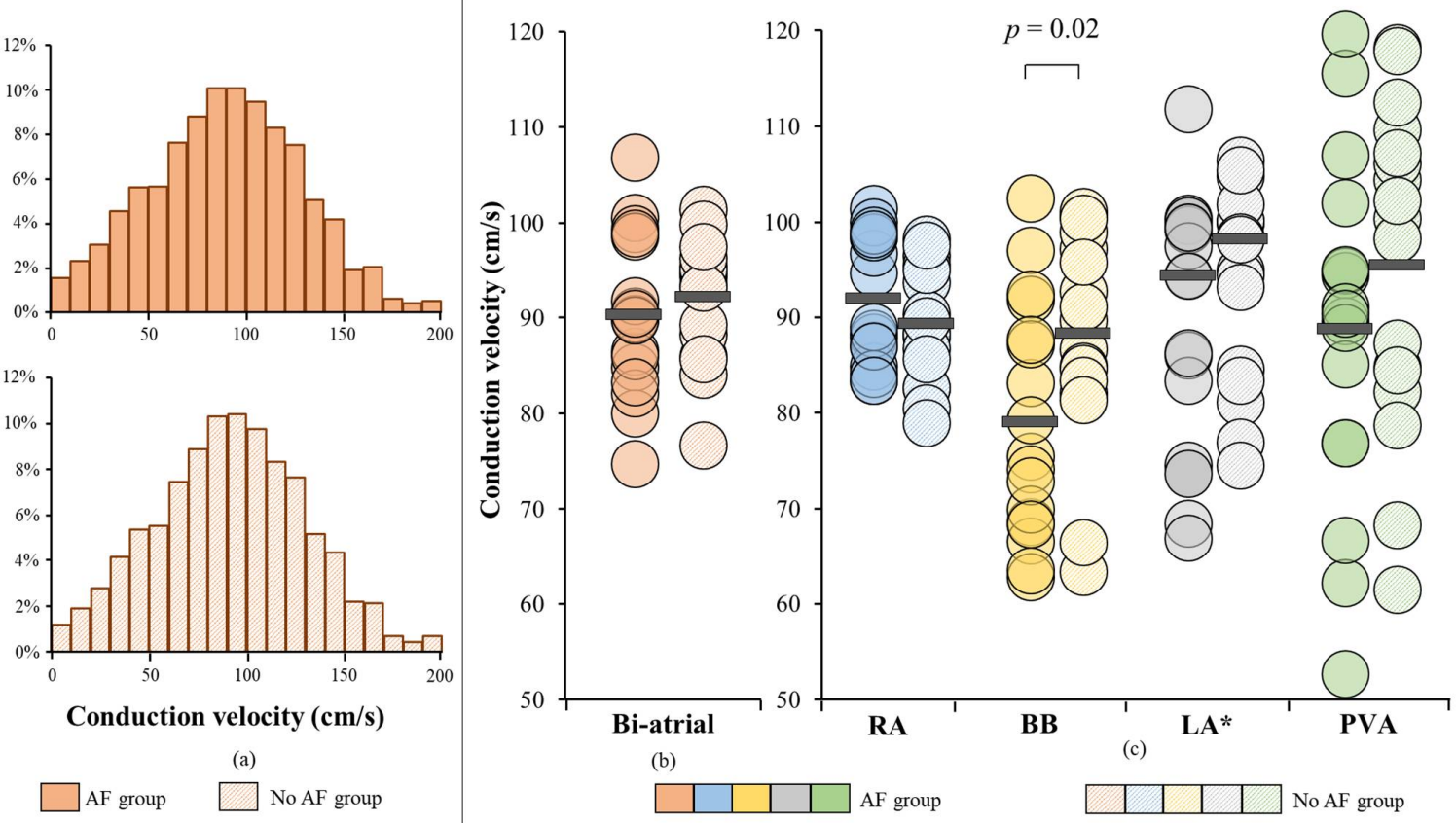

Figure 2. CV in patients with and without a history of AF. (a) biatrial CV histograms of patients with and without a history of AF; (b) biatrial median CV displayed for each patient (c) median CV displayed for each patient per region separately. *Non-normally distributed. $\mathrm{cm} / \mathrm{s}=$ centimeter/second; $\mathrm{CV}=$ conduction velocity; $\mathrm{AF}=$ atrial fibrillation; $\mathrm{BB}=\mathrm{Bachmann}$ 's Bundle; LA = left atrium; PVA = pulmonary vein area; RA = right atrium.

Biatrial median CV in the no AF group ranged from 77 to $107 \mathrm{~cm} / \mathrm{s}$ and in the AF group from 75 to $101 \mathrm{~cm} / \mathrm{s}$. There was no difference in biatrial median CV between both groups (AF: $90 \pm 8 \mathrm{~cm} / \mathrm{s}$ vs. no AF: $92 \pm 6 \mathrm{~cm} / \mathrm{s}, p=0.56$, Figure 2b). Additionally, variation of $C V$ was also comparable between the AF and no AF group $\left(\Delta \mathrm{P}_{5}-\mathrm{P}_{95}: 129 \pm 8 \mathrm{~ms}\right.$ vs. $129 \pm 10 \mathrm{~ms}, p=0.88$ ).

\subsection{AF-related Reduction of Conduction Velocity}

Figure 3 illustrates two examples of color-coded activation maps at BB obtained from a patient with a history of AF (a) and a patient without a history of AF (b). Corresponding $\mathrm{CV}$ maps are depicted next to the activation map. In the control patient, the SR wavefront encounters only some small areas of conduction delay, represented by crowding of isochrones in the left middle part of the array and right upper corner, resulting in a median $\mathrm{CV}$ of $101 \mathrm{~cm} / \mathrm{s}$. However, in the patient with a history of AF, a large area of slowing of conduction is present in the lower part of the activation map, resulting in a lower median 
$\mathrm{CV}$ of $88 \mathrm{~cm} / \mathrm{s}$. The lower panel of Figure 3 illustrates the corresponding relative frequency distribution of $\mathrm{CVs}$ at $\mathrm{BB}$ of the same patients.

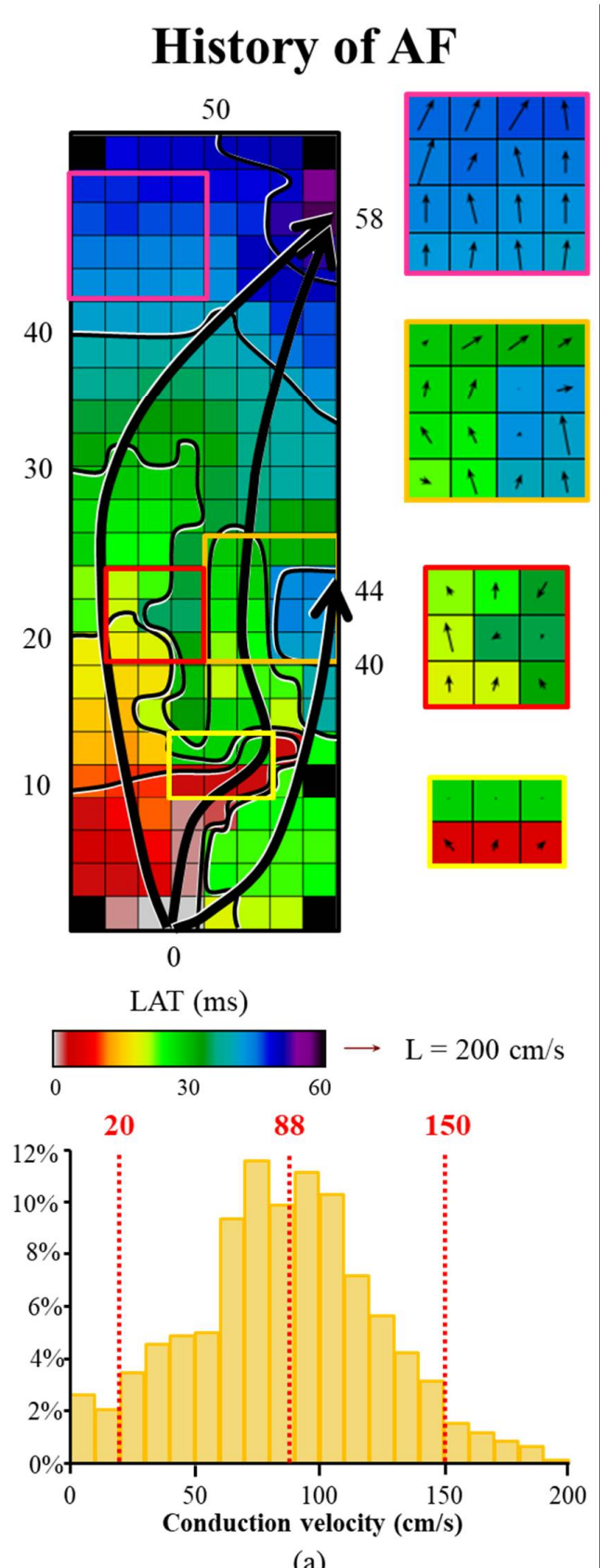

(a)

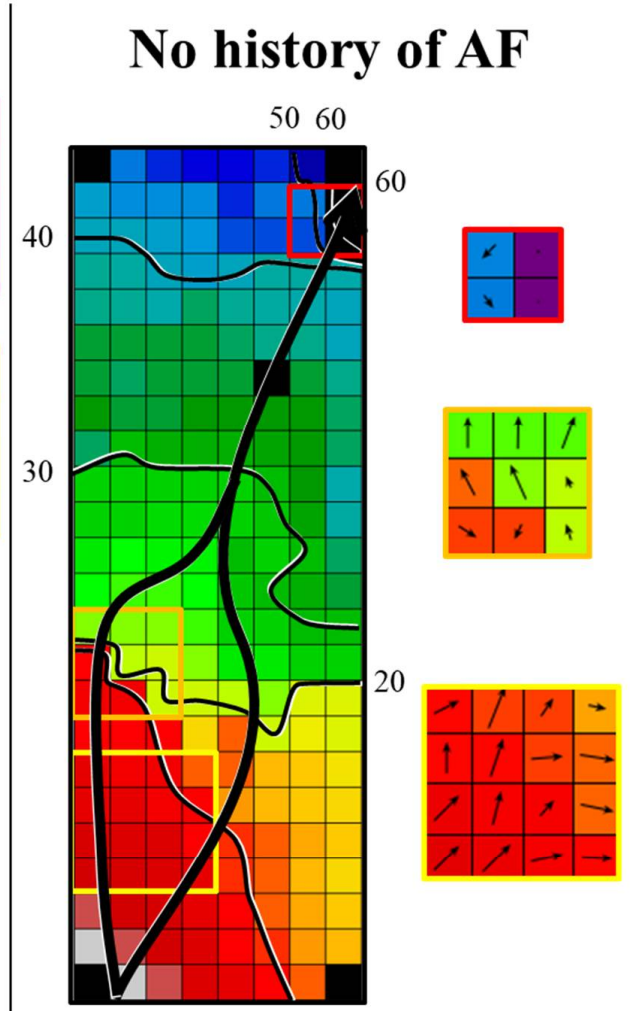

LAT (ms)

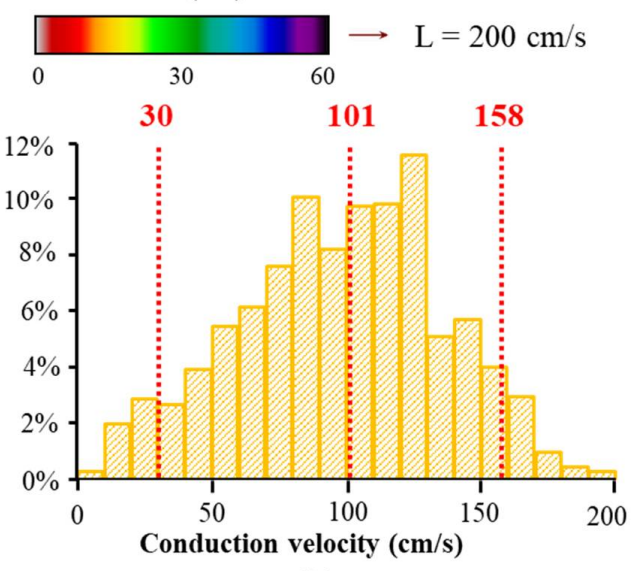

(b)

Figure 3. Color-coded activation maps and corresponding CV histograms at BB of a patient with and without a history of AF. The upper panel shows two examples of a color-coded activation maps at BB obtained from a patient with a history of $\mathrm{AF}(\mathbf{a})$ and a patient without a history of $\mathrm{AF}(\mathbf{b})$. Corresponding $\mathrm{CV}$ maps are depicted next to the activation map. CV vectors are depicted per electrode. In the patient with $\mathrm{AF}$, a large area of slowing of conduction is present in the lower part of the activation map, represented by crowding of isochrones. The colored boxes indicate smooth wavefront propagation (pink rectangle) and local conduction heterogeneities (yellow, red and orange rectangles). In the patient without $\mathrm{AF}$, the sinus rhythm wavefront encounters only some small areas of conduction delay (orange and red rectangles). Isochrones (black lines) drawn at $10 \mathrm{~ms}$. The black arrows indicates the main wave direction. Lower panel: corresponding CV histograms of the patient with $\mathrm{AF}$ (a) and without AF (b) recorded at BB. The dashed lines represent the 5th, 50th and 95th percentiles of the relative frequency distribution of CVs. $\mathrm{cm} / \mathrm{s}=$ centimeter $/$ second; $\mathrm{ms}=$ milliseconds; $\mathrm{BB}=$ Bachmann's bundle; $\mathrm{CV}=$ conduction velocity; $\mathrm{LAT}=$ local activation time. 
Figure 4 shows relative frequency distributions of CVs in the entire AF and no $\mathrm{AF}$ group for each location separately. Compared to patients without $\mathrm{AF}$, slowing of conduction was solely found at BB in patients with AF (BB: $79 \pm 12 \mathrm{~cm} / \mathrm{s}$ vs. $88 \pm 11 \mathrm{~cm} / \mathrm{s}, p=0.02$; RA: $92 \pm 7 \mathrm{~cm} / \mathrm{s}$ vs. $89 \pm 6 \mathrm{~cm} / \mathrm{s}, p=0.35$; PVA: $89 \pm 18 \mathrm{~cm} / \mathrm{s}$ vs. $96 \pm 17 \mathrm{~cm} / \mathrm{s}, p=0.32$, LA: $94 \mathrm{~cm} / \mathrm{s}(84-101)$ vs. $98 \mathrm{~cm} / \mathrm{s}(84-101), p=0.21$ ) (Figure 2C). However, as shown in Table 2, the variance of $\mathrm{CV}$ per location, including BB, was comparable between patients in the AF and no AF group (all $p \geq 0.05$ ).
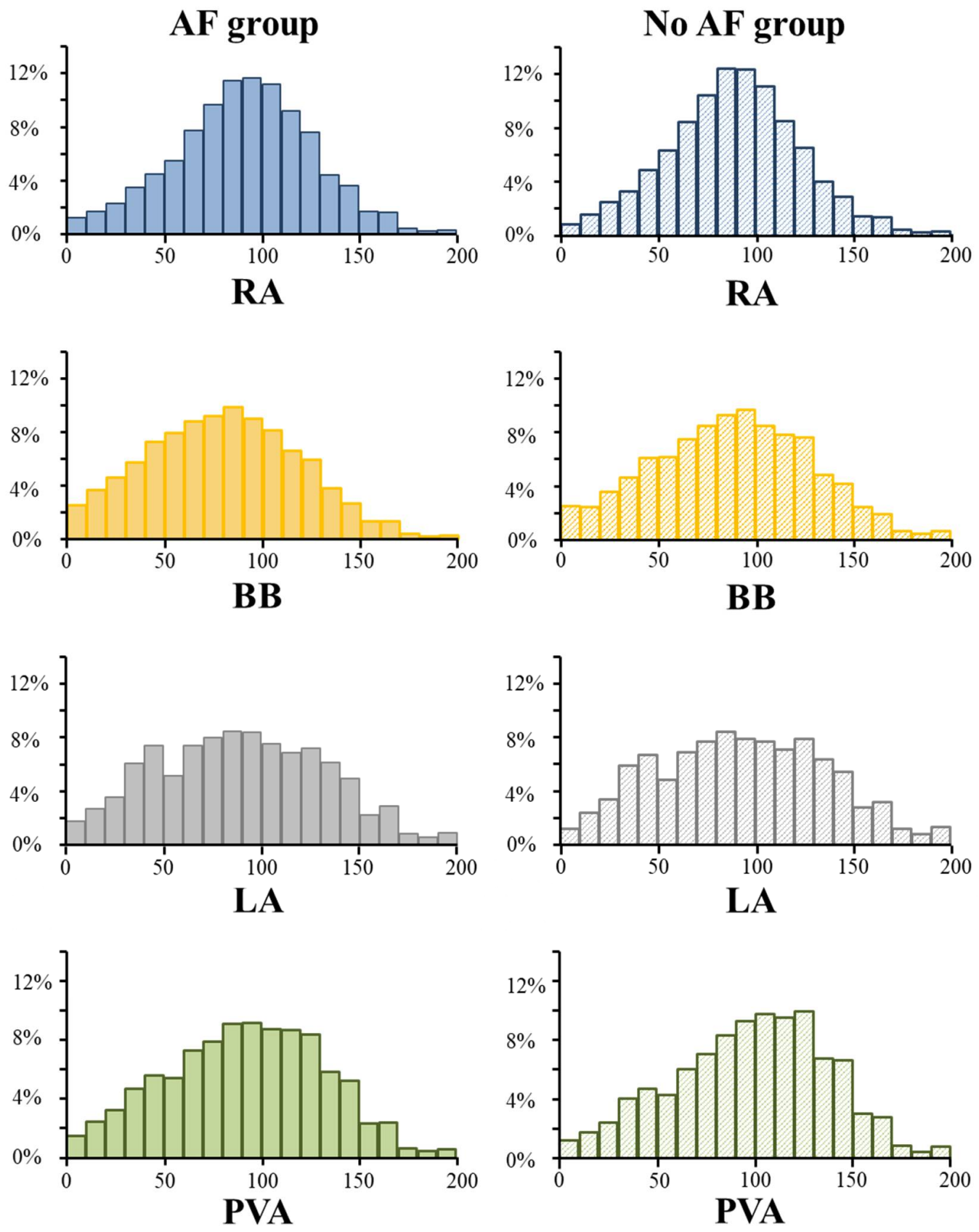

(a)

Conduction velocity $(\mathrm{cm} / \mathrm{s})$

(b)

Figure 4. CV histograms of the AF and no AF group. Relative frequency distributions of CVs in the AF (a) and no AF group (b) shown for each location separately. $\mathrm{cm} / \mathrm{s}=$ centimeter $/$ second; $\mathrm{AF}=$ atrial fibrillation; $\mathrm{BB}=\mathrm{Bachmann}$ 's Bundle; $\mathrm{LA}=$ left atrium; PVA = pulmonary vein area; $\mathrm{RA}=$ right atrium . 
Table 2. Variation of CV.

\begin{tabular}{cccc}
\hline & $\begin{array}{c}\text { AF Group } \\
(\boldsymbol{n}=\mathbf{1 7})\end{array}$ & $\begin{array}{c}\text { No AF Group } \\
(\boldsymbol{n}=\mathbf{1 7})\end{array}$ & $\boldsymbol{p}$ Value \\
\hline Variation of CV $\left(\Delta \mathrm{P}_{5}-\mathrm{P}_{95}\right)$ & & & \\
RA-cm/s (mean $\pm \mathrm{SD})$ & $118 \pm 9$ & $114 \pm 8$ & 0.14 \\
$\mathrm{BB}-\mathrm{cm} / \mathrm{s}$ (median $(\mathrm{IQR}))$ & $121(114-133)$ & $129(119-137)$ & 0.31 \\
PVA-cm/s (mean $\pm \mathrm{SD})$ & $129 \pm 12$ & $130 \pm 21$ & 0.87 \\
LA-cm/s (mean $\pm \mathrm{SD})$ & $139 \pm 11$ & $143 \pm 13$ & 0.42 \\
\hline
\end{tabular}

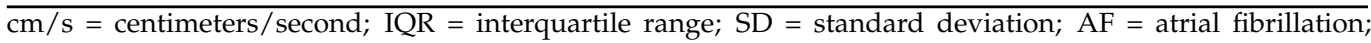
$\mathrm{BB}=$ Bachmann's bundle; $\mathrm{LA}=$ left atrium; $\mathrm{PVA}=$ pulmonary vein area; $\mathrm{RA}=$ right atrium .

Figure 5a shows for the AF and no AF group at which region the lowest $\mathrm{CV}$ (5th percentile of the $\mathrm{CV}$ histogram) within each patient occurred. In patients without $\mathrm{AF}$, there was no predilection site for the lowest CVs $\left(\mathrm{P}_{5}\right)(\mathrm{RA}: 12 \%, n=2 ; \mathrm{BB}: 29 \%, n=5 ; \mathrm{LA}: 29 \%$, $n=5$; PVA: $29 \%, n=5)$. In patients with AF, lowest CV was most often measured at BB $(53 \%, n=9)$ and were also measured at the LA $(18 \%, n=3)$ and PVA $(29 \%, n=5)$, but not at the RA (RA: $0 \%, n=0)$ ). Figure $5 \mathrm{~b}$ shows the distribution of the lowest $\mathrm{CV}$ for each location separately. At BB, the lowest CV (interquartile range) ranged between 15 and $22 \mathrm{~cm} / \mathrm{s}$ (median $20 \mathrm{~cm} / \mathrm{s}$ ), while in the no AF group it ranged between 23 and $31 \mathrm{~cm} / \mathrm{s}$ (median: $28 \mathrm{~cm} / \mathrm{s}$ ). At the RA, LA and PVA, lowest CVs are comparable between the AF and no AF group.

AF group

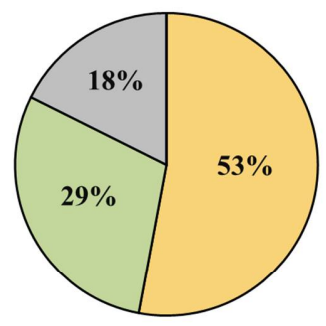

RA

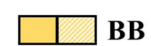

\section{No AF group}

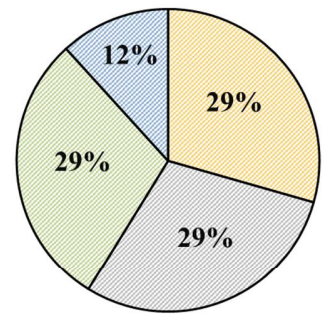

10 LA

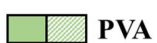

PVA

(a)

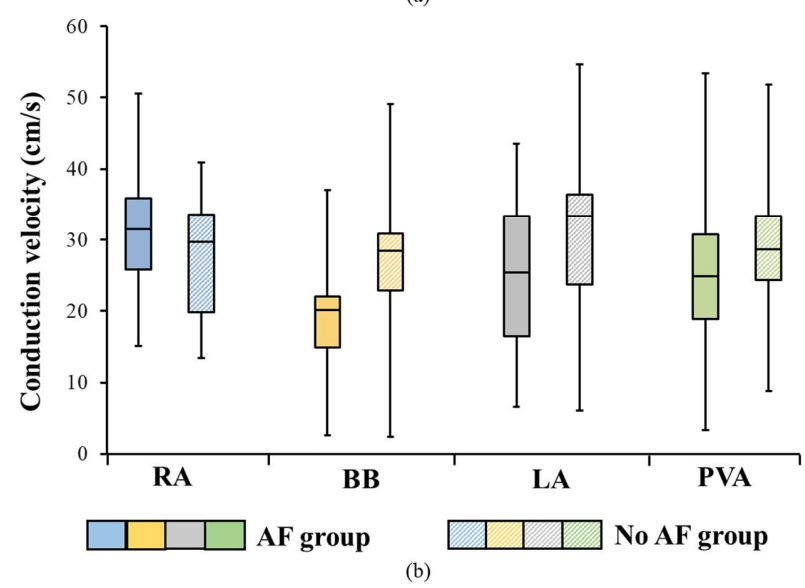

Figure 5. Predilection site for the lowest CV (a) Location of the lowest CV (defined as the 5th percentile of the relative frequency distribution of $\mathrm{CV}$ ), within each AF patient (left) and no AF patient (right); (b) Distribution of the lowest CVs shown for each location separately. $\mathrm{cm} / \mathrm{s}=$ centimeter/second; $\mathrm{AF}=$ atrial fibrillation; $\mathrm{BB}=$ Bachmann's Bundle; LA = left atrium; $\mathrm{PVA}=$ pulmonary vein area; $\mathrm{RA}=$ right atrium . 


\subsection{Relation between Conduction Heterogeneity and Total Activation Time}

Figure 6 illustrates for each patient the TAT (a) and the TAT per region separately (b). AF was associated with a prolonged TAT $(156 \pm 21 \mathrm{~ms} v \mathrm{vs} .120 \pm 22 \mathrm{~ms}, p<0.001)$ and TAT was particularly prolonged at $\mathrm{BB}(76 \pm 31 \mathrm{~ms}$ vs. $58 \pm 23 \mathrm{~ms}, p=0.03)$.

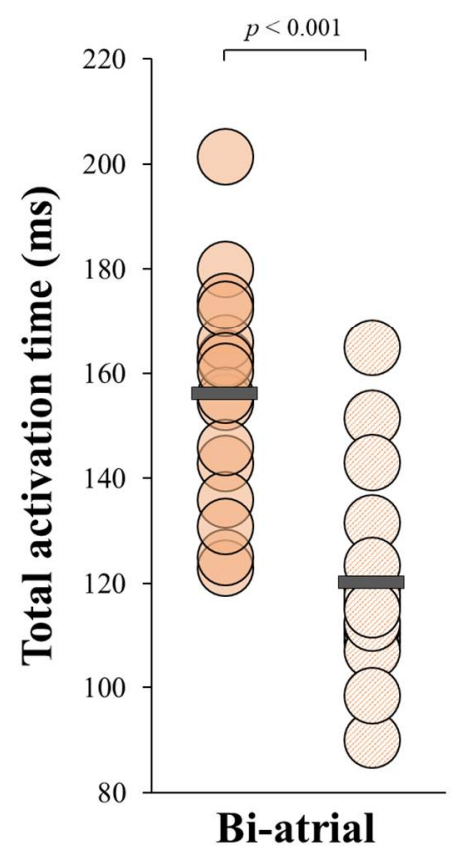

(a)

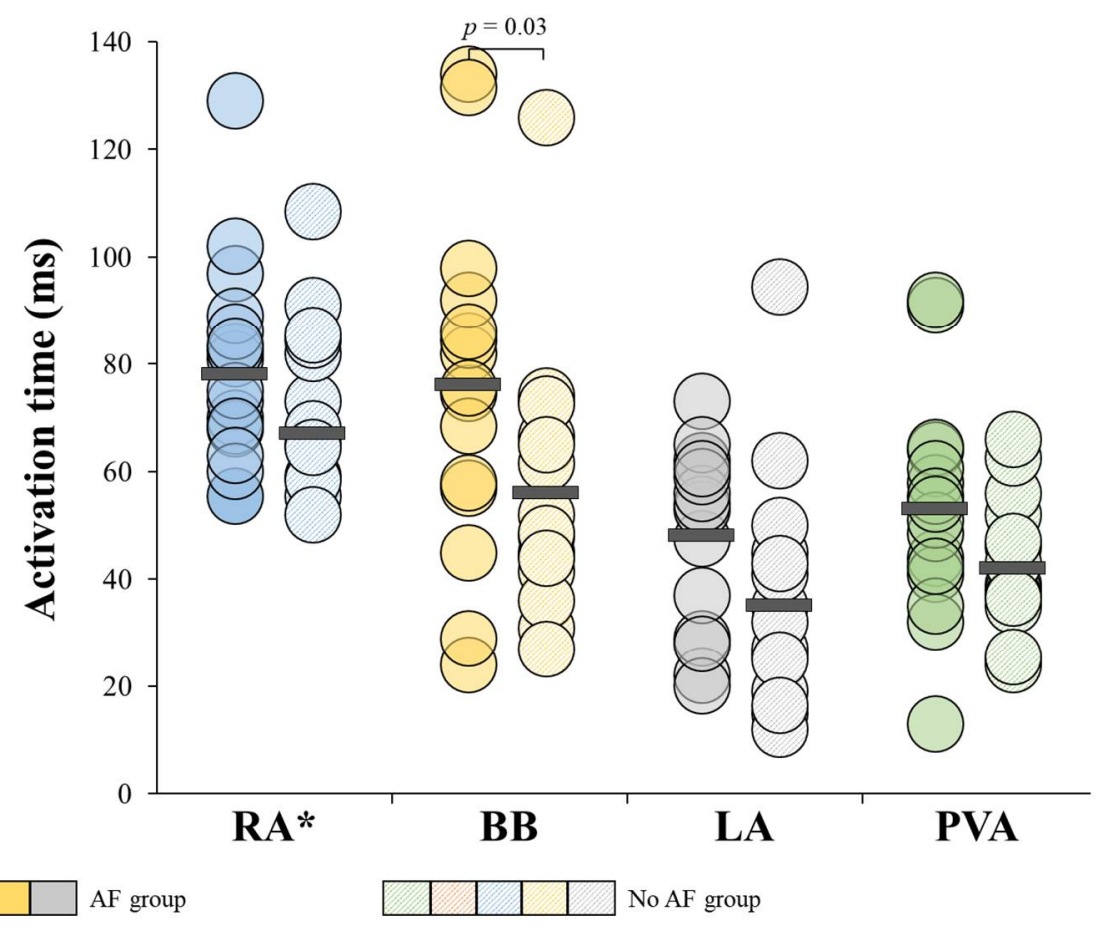

(b)

Figure 6. TAT displayed for each individual patient for the entire atria and per region separately (a) Biatrial TAT displayed for each individual patient; (b) TAT displayed for each patient per region separately. * Non-normally distributed. $\mathrm{ms}=$ milliseconds; $\mathrm{BB}=$ Bachmann's Bundle; $\mathrm{LA}=$ left atrium; PVA = pulmonary vein area; TAT = total activation time; $\mathrm{RA}=$ right atrium .

\subsection{Atrial Fibrillation Episodes and Unipolar Voltages}

The lowest voltages (5th percentiles of the voltage histogram) differed between the AF and no AF group only at BB (Table 3). Patients in the AF group had a low voltage of $0.9 \pm 0.6 \mathrm{mV}$ at this location, whereas in the control group it was $1.5 \pm 0.9 \mathrm{mV}(p=0.02)$. The lowest voltages did not differ between both groups at RA, PVA and LA (all $p \geq 0.05$ ).

Table 3. The lowest unipolar voltages presented for the AF and no AF group.

\begin{tabular}{cccc}
\hline & $\begin{array}{c}\text { AF Group } \\
(\boldsymbol{n}=\mathbf{1 7})\end{array}$ & $\begin{array}{c}\text { No AF Group } \\
(\boldsymbol{n}=\mathbf{1 7})\end{array}$ & $p$ Value \\
\hline 5th percentiles of unipolar voltages & & & \\
Bi-atrial-mV (median (IQR)) & $0.6(0.6-1.0)$ & $0.8(0.6-1.1)$ & 0.44 \\
RA-mV (median (IQR)) & $1.1 \pm 0.6$ & $0.9 \pm 0.3$ & 0.20 \\
BB-mV (mean \pm SD) & $0.9 \pm 0.6$ & $1.5 \pm 0.9$ & 0.02 \\
PVA-mV (mean \pm SD) & $0.6(0.5-1.4)$ & $1.4(0.6-2.7)$ & 0.08 \\
LA-mV (mean \pm SD) & $1.2 \pm 0.7$ & $1.2 \pm 0.7$ & 0.83
\end{tabular}

$\overline{\mathrm{IQR}}$ = interquartile range; $\mathrm{SD}$ = standard deviation; $\mathrm{AF}=$ history of AF; $\mathrm{BB}=$ Bachmann's bundle; $\mathrm{LA}$ = left atrium; $\mathrm{PVA}=$ pulmonary vein area; $\mathrm{RA}=$ right atrium .

\section{Discussion}

\subsection{Key Findings}

This high-resolution intraoperative mapping study is the first to explore the association between $\mathrm{CV}$ and a history of AF in both atria. $\mathrm{CV}$ was reduced in the AF group only at $\mathrm{BB}$. However, the variance of $\mathrm{CV}$ was comparable between both groups at this site. $\mathrm{BB}$ 
was also a predilection site for slowing of conduction in the AF group, as the lowest CVs were mostly located at this site. In patients without AF, the lowest CVs were found at all locations. Moreover, TAT was prolonged and voltages were decreased at BB in patients with AF. AF was not associated with a reduced CV, a prolonged TAT or lower voltages at the RA, PVA and LA.

\subsection{Reduced Conduction Velocity as a Prerequisite for AF Onset}

AF is the most common arrhythmia and induces both electrical and structural remodeling $[15,16]$. Longer duration of AF increases the degree of structural and electrical remodeling $[17,18]$. Electrical remodeling consists of alterations in ion channel expression and is reversible within one week of SR [16,19-24]. Structural remodeling consists of atrial fibrosis and side-to-side cell uncoupling and is still or partially present after 4 months of SR [24-27]. Both remodeling processes affect intra-atrial CV and may explain the increased vulnerability to AF. In the present study, we measure immediately after ECV, which means that both electrical and structural remodeling are present. After AF termination, it is generally assumed that the combination of increased dispersion of the refractory period and a reduced CV in combination with the presence of triggers such as premature beats may increase the susceptibility to AF recurrence.

As previously mentioned, the average CV measured during SR at the right atrial free wall in patients without atrial remodeling is $88 \pm 9 \mathrm{~cm} / \mathrm{s}$ [4]. A similar CV of $89 \pm 13 \mathrm{~cm} / \mathrm{s}$ was found at BB in 185 patients undergoing coronary artery bypass surgery, of whom only 13 had paroxysmal AF [5]. Comparing these CVs to the CV in our no AF group, our results are comparable at $\mathrm{RA}$ and $\mathrm{BB}$ with a median $\mathrm{CV}$ of $89 \pm 6 \mathrm{~cm} / \mathrm{s}$ and $88 \pm 11 \mathrm{~cm} / \mathrm{s}$, respectively.

In our AF group, $\mathrm{CV}$ was reduced and TAT was prolonged only at BB compared to patients without AF. Previously, we determined the most accurate methodology to measure local conduction heterogeneity and, as a sub-analysis, we determined the median CV at all locations in patients with paroxysmal AF and no AF [14]. Subsequently, we also found a reduced $\mathrm{CV}$ at $\mathrm{BB}$ in patients without $\mathrm{AF}$ [14]. However, in that study we did not include patients with persistent or longstanding persistent AF who have varying degrees of atrial remodeling. In addition, confounders of intra-atrial conduction, such as age, body mass index and left atrial enlargement, were not considered [7-9]. Patients were significantly older in the paroxysmal AF group (71 \pm 9 years vs. $66 \pm 10$ years, $p<0.001)$ and more patients had left atrial enlargement (41\% vs. 19\%,<0.001) [14]. Another study, performed by Zheng et al., compared the average CV at the RA and LA between patients with paroxysmal AF and control patients with respectively atrioventricular nodal re-entry tachycardia and Wolff-Parkinson White syndrome using three-dimensional endocardial mapping [6]. In that study, a history of AF was associated with a reduced CV at both locations which was more pronounced at the LA than the RA [6]. Remarkably, CV was much lower than our findings in the AF group (LA: $50 \mathrm{~cm} / \mathrm{s}$ vs. $94 \mathrm{~cm} / \mathrm{s}$; RA: $60 \mathrm{~cm} / \mathrm{s}$ vs. $92 \mathrm{~cm} / \mathrm{s}$ ). To estimate $\mathrm{CV}$, they only compared a triplet of sites, when we computed, for each atrial potential, an average of velocity estimations between all eight adjacent electrodes [6,14]. Furthermore, those triplet numbers of locations were not measured simultaneously during the same beat, as we did in our study with the 128- or 192 electrode array [6]. It is likely that the CV measured in our study population is more accurate and therefore did not show a difference in CV at the RA and LA between patients with and without AF. In addition, no measurements were made of the PVA and BB and the study population was underpowered with only six paroxysmal AF patients for comparison [6].

We only evaluated regional differences in $\mathrm{CV}$ between patients with and without AF and not specific areas within each region. As previously mentioned, CV is determined, among other things, by wavefront geometry and muscle thickness [1,2]. The smooth, apparently uniform walls of the LA are composed of multiple layers of differently aligned myocardial fibers, with marked regional variations in thickness [28,29]. In the RA, muscular bundles are larger, e.g., the terminal crest, and as a result of the presence of pectinate 
muscles, the RA wall is not uniform in thickness [30]. In normal hearts, inhomogeneities are already present in both gross structure and myoarchitecture [30]. Future studies should investigate whether there is a relation between the magnitude of $\mathrm{CV}$ and specific anatomic features in patients with AF.

\subsection{Bachmann's Bundle as a Predilection Site for Atrial Fibrillation}

The propagation of wavefronts occurs preferably and more rapidly along longitudinal cardiac fibers instead of perpendicular to them [31,32]. BB has parallel aligned muscle bundles, making it the preferred route for interatrial conduction [33]. BB is also believed to play an important role in the pathophysiology of AF [34,35]. Clinical studies have found an association between interatrial block and development of AF [34,36]. In our study, patients with AF had a reduced CV with TAT prolongation at this site. A histological examination of 10 hearts from patients with paroxysmal AF and 10 hearts from patients without AF showed that fibro-fatty tissue was much more extensive in patients with AF [37]. This can lead to a disruption of cell-to-cell connections, disturbed wavefront geometry and thus a reduced $\mathrm{CV}$ and prolonged TAT.

\subsection{Low Voltages and Atrial Fibrillation}

Low-voltage areas are a commonly used surrogate marker for the presence of atrial fibrosis, which plays a key role in the maintenance of AF [38]. Atrial fibrosis, in turn, affects local CV by forming 'zig-zag' like conduction paths, leading to anisotropy and thus a reduced CV [1]. In the present study, we did not correlate low-voltage areas with $\mathrm{CV}$, as it remains very challenging to identify a correct threshold to define low-voltage areas. Additionally, prior high-resolution epicardial mapping studies demonstrated no clear relationship between CV and low voltage areas [14,39]. In our study population, in general we have found lower voltages at BB in patients with AF compared to patients without AF.

\subsection{Study Limitations}

Patients in the AF group may have had varying degrees of atrial remodeling as some patients had persistent or longstanding persistent AF, while other patients had paroxysmal AF. In addition, in the AF group, SR recordings were made immediately after $\mathrm{ECV}$, resulting in a different degree of electrical remodeling. Furthermore, this is a single center observational study with a small amount of patients. There is a risk of selection bias. Moreover, at different sinus rates, different exit pathways occur that can affect the CV. Direction-dependent CV heterogeneities could be missed as we only analyzed SR.

\section{Conclusions}

This high-resolution intraoperative mapping study is the first to examine the association between $\mathrm{CV}$ and a history of AF in both atria. At BB only, CV was reduced in the AF group. However, the variance of $\mathrm{CV}$ was comparable between both groups at this site. Additionally, BB was also a predilection site for slowing of conduction in the AF group, as the lowest $\mathrm{CV}$ was mostly located at this site. Moreover, the TAT was prolonged and voltages were decreased at $\mathrm{BB}$ in patients with AF. The next step will be to determine the relevance of a reduced $\mathrm{CV}$ at $\mathrm{BB}$ in relation to $\mathrm{AF}$ development and maintenance.

Author Contributions: Conceptualization, A.H. and N.M.S.d.G.; methodology, A.H., M.S.v.S. and N.M.S.d.G.; validation, A.H. and N.M.S.d.G.; formal analysis, A.H. and N.M.S.d.G.; investigation, A.H.; resources, A.H., M.S.v.S., W.F.B.v.d.D., N.M.S.d.G., Y.J.H.J.T. and A.J.J.C.B.; data curation, A.H., N.M.S.d.G., M.S.v.S. and W.F.B.v.d.D.; writing—original draft preparation, A.H.; writing-review and editing, N.M.S.d.G., A.J.J.C.B., M.S.v.S., W.F.B.v.d.D. and Y.J.H.J.T.; visualization, A.H. and N.M.S.d.G.; supervision, N.M.S.d.G. and A.J.J.C.B.; project administration, A.H.; funding acquisition, N.M.S.d.G. All authors have read and agreed to the published version of the manuscript. 
Funding: N.M.S.d.G. is supported by funding grants from CVON-AFFIP (914728), NWO-Vidi (91717339), Biosense Webster USA (ICD 783454) and Medical Delta. This research (IIS-331) was conducted with financial support from the Investigator-Initiated Study Program of Biosense Webster, Inc.

Institutional Review Board Statement: The study was conducted according to the guidelines of the Declaration of Helsinki and approved by the institutional Medical Ethical Committee (resp. MEC 2010-054 [10] and MEC 2014-393 [11]).

Informed Consent Statement: Informed consent was obtained from all subjects involved in the study.

Acknowledgments: The authors would like to kindly thank our colleagues A. Yaksh; C.P. Teuwen; E.A.H. Lanters; J.M.E. van der Does; E.M.J.P. Mouws; C.A. Houck; R. Starreveld; C.S. Serban; R.K. Kharbanda; L.N. van Staveren for their help with acquiring the mapping data and we also kindly would like to thank the cardiothoracic surgeons J.A. Bekkers; W.J. van Leeuwen; F.B.S. Oei; F.R.N. van Schaagen; P.C. van de Woestijne for their contribution to this work.

Conflicts of Interest: The authors declare no conflict of interest.

\section{References}

1. Kleber, A.G.; Rudy, Y. Basic mechanisms of cardiac impulse propagation and associated arrhythmias. Physiol. Rev. 2004, 84, 431-488. [CrossRef] [PubMed]

2. Rossi, S.; Gaeta, S.; Griffith, B.E.; Henriquez, C.S. Muscle thickness and curvature influence atrial conduction velocities. Front. Physiol. 2018, 9, 1344. [CrossRef] [PubMed]

3. King, J.H.; Huang, C.L.; Fraser, J.A. Determinants of myocardial conduction velocity: Implications for arrhythmogenesis. Front. Physiol. 2013, 4, 154. [CrossRef] [PubMed]

4. Hansson, A.; Holm, M.; Blomstrom, P.; Johansson, R.; Luhrs, C.; Brandt, J.; Olsson, S.B. Right atrial free wall conduction velocity and degree of anisotropy in patients with stable sinus rhythm studied during open heart surgery. Eur. Heart J. 1998, 19, 293-300. [CrossRef] [PubMed]

5. Teuwen, C.P.; Yaksh, A.; Lanters, E.A.; Kik, C.; van der Does, L.J.; Knops, P.; Taverne, Y.J.; van de Woestijne, P.C.; Oei, F.B.; Bekkers, J.A.; et al. Relevance of conduction disorders in bachmann's bundle during sinus rhythm in humans. Circ. Arrhythmia Electrophysiol. 2016, 9, e003972. [CrossRef] [PubMed]

6. Zheng, Y.; Xia, Y.; Carlson, J.; Kongstad, O.; Yuan, S. Atrial average conduction velocity in patients with and without paroxysmal atrial fibrillation. Clin. Physiol. Funct. Imaging 2017, 37, 596-601. [CrossRef] [PubMed]

7. $\quad$ van der Does, W.F.B.; Houck, C.A.; Heida, A.; van Schie, M.S.; van Schaagen, F.R.N.; Taverne, Y.; Bogers, A.; de Groot, N.M.S. Atrial electrophysiological characteristics of aging. J. Cardiovasc. Electrophysiol. 2021, 32, 903-912. [CrossRef] [PubMed]

8. Schram-Serban, C.; Heida, A.; Roos-Serote, M.C.; Knops, P.; Kik, C.; Brundel, B.; Bogers, A.; de Groot, N.M.S. Heterogeneity in conduction underlies obesity-related atrial fibrillation vulnerability. Circ. Arrhythmia Electrophysiol. 2020, 13, e008161. [CrossRef] [PubMed]

9. Schotten, U.; Verheule, S.; Kirchhof, P.; Goette, A. Pathophysiological mechanisms of atrial fibrillation: A translational appraisal. Physiol. Rev. 2011, 91, 265-325. [CrossRef] [PubMed]

10. van der Does, L.; Yaksh, A.; Kik, C.; Knops, P.; Lanters, E.A.H.; Teuwen, C.P.; Oei, F.B.S.; van de Woestijne, P.C.; Bekkers, J.A.; Bogers, A.; et al. Quest for the arrhythmogenic substrate of atrial fibrillation in patients undergoing cardiac surgery (quasar study): Rationale and design. J. Cardiovasc. Transl. Res. 2016, 9, 194-201. [CrossRef] [PubMed]

11. Lanters, E.A.; van Marion, D.M.; Kik, C.; Steen, H.; Bogers, A.J.; Allessie, M.A.; Brundel, B.J.; de Groot, N.M. Halt \& reverse: Hsf1 activators lower cardiomyocyt damage; towards a novel approach to reverse atrial fibrillation. J. Transl. Med. 2015, 13, 347.

12. Yaksh, A.; Kik, C.; Knops, P.; Roos-Hesselink, J.W.; Bogers, A.J.; Zijlstra, F.; Allessie, M.; de Groot, N.M. Atrial fibrillation: To map or not to map? Neth. Heart J. 2014, 22, 259-266. [CrossRef]

13. Mouws, E.; van der Does, L.; Kik, C.; Lanters, E.A.H.; Teuwen, C.P.; Knops, P.; Bogers, A.; de Groot, N.M.S. Impact of the arrhythmogenic potential of long lines of conduction slowing at the pulmonary vein area. Heart Rhythm 2019, 16, 511-519. [CrossRef]

14. Van Schie, M.S.; Heida, A.; Taverne, Y.; Bogers, A.; de Groot, N.M.S. Identification of local atrial conduction heterogeneities using high-density conduction velocity estimation. Europace 2021, euab088. [CrossRef]

15. Allessie, M.; Ausma, J.; Schotten, U. Electrical, contractile and structural remodeling during atrial fibrillation. Cardiovasc. Res. 2002, 54, 230-246. [CrossRef]

16. Wijffels, M.C.; Kirchhof, C.J.; Dorland, R.; Allessie, M.A. Atrial fibrillation begets atrial fibrillation. A study in awake chronically instrumented goats. Circulation 1995, 92, 1954-1968. [CrossRef]

17. Ausma, J.; Litjens, N.; Lenders, M.H.; Duimel, H.; Mast, F.; Wouters, L.; Ramaekers, F.; Allessie, M.; Borgers, M. Time course of atrial fibrillation-induced cellular structural remodeling in atria of the goat. J. Mol. Cell. Cardiol. 2001, 33, 2083-2094. [CrossRef]

18. Schotten, U.; Duytschaever, M.; Ausma, J.; Eijsbouts, S.; Neuberger, H.R.; Allessie, M. Electrical and contractile remodeling during the first days of atrial fibrillation go hand in hand. Circulation 2003, 107, 1433-1439. [CrossRef] 
19. Gaspo, R.; Bosch, R.F.; Bou-Abboud, E.; Nattel, S. Tachycardia-induced changes in $\mathrm{Na}^{+}$current in a chronic dog model of atrial fibrillation. Circ. Res. 1997, 81, 1045-1052. [CrossRef]

20. Yue, L.; Feng, J.; Gaspo, R.; Li, G.R.; Wang, Z.; Nattel, S. Ionic remodeling underlying action potential changes in a canine model of atrial fibrillation. Circ. Res. 1997, 81, 512-525. [CrossRef]

21. Bosch, R.F.; Zeng, X.; Grammer, J.B.; Popovic, K.; Mewis, C.; Kuhlkamp, V. Ionic mechanisms of electrical remodeling in human atrial fibrillation. Cardiovasc. Res. 1999, 44, 121-131. [CrossRef]

22. Van Wagoner, D.R.; Pond, A.L.; Lamorgese, M.; Rossie, S.S.; McCarthy, P.M.; Nerbonne, J.M. Atrial l-type Ca ${ }^{2+}$ currents and human atrial fibrillation. Circ. Res. 1999, 85, 428-436. [CrossRef]

23. Van Wagoner, D.R.; Pond, A.L.; McCarthy, P.M.; Trimmer, J.S.; Nerbonne, J.M. Outward K ${ }^{+}$current densities and kv1.5 expression are reduced in chronic human atrial fibrillation. Circ. Res. 1997, 80, 772-781. [CrossRef]

24. Everett, T.H.; Li, H.; Mangrum, J.M.; McRury, I.D.; Mitchell, M.A.; Redick, J.A.; Haines, D.E. Electrical, morphological, and ultrastructural remodeling and reverse remodeling in a canine model of chronic atrial fibrillation. Circulation 2000, 102, 1454-1460. [CrossRef]

25. Spach, M.S.; Boineau, J.P. Microfibrosis produces electrical load variations due to loss of side-to-side cell connections: A major mechanism of structural heart disease arrhythmias. Pacing Clin. Electrophysiol. 1997, 20, 397-413. [CrossRef]

26. Darby, A.E.; Dimarco, J.P. Management of atrial fibrillation in patients with structural heart disease. Circulation 2012, 125, 945-957. [CrossRef]

27. Psaty, B.M.; Manolio, T.A.; Kuller, L.H.; Kronmal, R.A.; Cushman, M.; Fried, L.P.; White, R.; Furberg, C.D.; Rautaharju, P.M. Incidence of and risk factors for atrial fibrillation in older adults. Circulation 1997, 96, 2455-2461. [CrossRef]

28. Wang, K.; Ho, S.Y.; Gibson, D.G.; Anderson, R.H. Architecture of atrial musculature in humans. Br. Heart J. 1995, 73, 559-565. [CrossRef]

29. Ho, S.Y.; Sanchez-Quintana, D.; Cabrera, J.A.; Anderson, R.H. Anatomy of the left atrium: Implications for radiofrequency ablation of atrial fibrillation. J. Cardiovasc. Electrophysiol. 1999, 10, 1525-1533.

30. Ho, S.Y.; Anderson, R.H.; Sanchez-Quintana, D. Atrial structure and fibres: Morphologic bases of atrial conduction. Cardiovasc. Res. 2002, 54, 325-336. [CrossRef]

31. Roberts, D.E.; Hersh, L.T.; Scher, A.M. Influence of cardiac fiber orientation on wavefront voltage, conduction velocity, and tissue resistivity in the dog. Circ. Res. 1979, 44, 701-712. [CrossRef] [PubMed]

32. Spach, M.S.; Miller, W.T., 3rd; Geselowitz, D.B.; Barr, R.C.; Kootsey, J.M.; Johnson, E.A. The discontinuous nature of propagation in normal canine cardiac muscle. Evidence for recurrent discontinuities of intracellular resistance that affect the membrane currents. Circ. Res. 1981, 48, 39-54. [CrossRef] [PubMed]

33. Bachmann, G. The inter-auricular time interval. Am. J. Physiol. 1916, 41, 309-320. [CrossRef]

34. Agarwal, Y.K.; Aronow, W.S.; Levy, J.A.; Spodick, D.H. Association of interatrial block with development of atrial fibrillation. Am. J. Cardiol. 2003, 91, 882. [CrossRef]

35. Duytschaever, M.; Danse, P.; Eysbouts, S.; Allessie, M. Is there an optimal pacing site to prevent atrial fibrillation?: An experimental study in the chronically instrumented goat. J. Cardiovasc. Electrophysiol. 2002, 13, 1264-1271. [CrossRef]

36. Ariyarajah, V.; Fernandes, J.; Kranis, M.; Apiyasawat, S.; Mercado, K.; Spodick, D.H. Prospective evaluation of atrial tachyarrhythmias in patients with interatrial block. Int. J. Cardiol. 2007, 118, 332-337. [CrossRef]

37. Becker, A.E. How structurally normal are human atria in patients with atrial fibrillation? Heart Rhythm 2004, 1, 627-631. [CrossRef]

38. Sim, I.; Bishop, M.; O’Neill, M.; Williams, S.E. Left atrial voltage mapping: Defining and targeting the atrial fibrillation substrate. J. Interv. Card. Electrophysiol. 2019, 56, 213-227. [CrossRef]

39. Van Schie, M.S.; Starreveld, R.; Bogers, A.; de Groot, N.M.S. Sinus rhythm voltage fingerprinting in patients with mitral valve disease using a high-density epicardial mapping approach. Europace 2021, 23, 469-478. [CrossRef] 